ORDINES MILITARES

COLLOQUIA TORUNENSIA HISTORICA

Yearbook for the Study of the Military Orders

ISSN (print) 0867-2008 / ISSN (online) 2391-7512

DOI: http://dx.doi.org/10.12775/OM.2016.009

pp. 171-188

\title{
LÁsZló PósÁN
}

Debreceni Egyetem

Történelmi Intézet

Egyetem tér 1

H-4032 Debrecen

Hungary

posan.laszlo@arts.unideb.hu

\section{DER LETZTE VERSUCH DES DEUTSCHEN ORDENS ZUR RÜCKKEHR NACH UNGARN (1702-1731)}

\section{KeYwords}

Military Orders; Teutonic Order; Hungary; Thurkish Wars; I8th century; European policy

achdem der ungarische König Andreas II. I 2 I I dem Deutschen Orden das Burzenland (ung. Barcaság) im südöstlichen Siebenbürgen geschenkt und später den Orden wegen seiner Selbstständigkeitsbestrebungen aus dem Land vertrieben hatte (I225), ${ }^{1}$ versuchte der Orden wiederholt

1 Über die Niederlassung des Ordens in Burzenland und seine Vertreibung von dort siehe: M. Perlbach, Der Deutsche Orden in Siebenbürgen, Mitteilungen des Instituts für Österreichische Geschichte 26 (1905), S. 415-430; G. E. Müller, Die Ursachen der Vertreibung des Deutschen Ordens aus Burzenland und Kumanien im Jahre 1225, Korrespondenzblatt des Vereins für siebenbürgische Landeskunde 48 (1925), 6-8, S. 42-68; G. Adriányi, Zur Geschichte des Deutschen Ritterordens in Siebenbürgen, Ungarn-Jahrbuch 3 (1971), S. 9-22; H. Glassl, Der Deutsche Orden in Burzenland und in Kumanien (1211-1225), Ungarn-Jahrbuch 3 (1971), S. 26-47; A. Prox, Die Burgen des Deutschen Ordens in Siebenbürgen, Siebenbürgisches Archiv 1 (1962), S. 29-62; W. Horvath, Die Deutschordensburgen des Burzenlandes, Deutsches Archiv für Landes- und Volksforschung 7 (1943), S. 446-452; F. Martini, Der Deutsche Ritterorden und seine Kolonisten im Burzenland, Ungarn-Jahrbuch 10 (1979), S. 41-57; S. Papcostea, Terra Borza et ultra montes nivium. Ein gescheiterter Kirchenstaat und sein Nachlass, Siebenbürgisches Archiv 42 (2013), S. 30-39; H. Zimmermann, Der Deutsche Orden in Burzenland. Eine diplomatische Untersuchung, Köln-Weimar-Wien 2000; P. Srodecki, Antemurale Christianitatis.

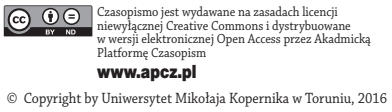


nach Ungarn zurückzukehren. Auf Bitten des Ordens ersuchte der Papst mehrmals die ungarischen Könige, dem vertriebenen Orden seine Güter im Burzenland zurückzugeben. ${ }^{2}$ Während des I 4. Jahrhunderts, in der Zeit der Herrschaft der Anjou-Könige, die wegen ihrer familiären Beziehungen Alliierte und nach dem Tod von Kasimir III. Inhaber der polnischen Krone waren, hatte der Orden, der die böhmische Dynastie der Luxemburger unterstützte, keine Möglichkeit, seine ehemaligen Güter in Siebenbürgen zurückzubekommen. ${ }^{3}$ Aber während der Herrschaft von Sigismund von Luxemburg (1387-1437) hatte der Orden durchaus reale Chancen zur Rückkehr nach Ungarn. Sigismund wollte den Orden wegen der türkischen Bedrohung mit der Verteidigung der Südgrenze beauftragen und bot dem Hochmeister im Jahre 1429 statt der Güter im Burzenland das Severiner Land (ung. Szörénység) und unterschiedliche Einkommensquellen für die Finanzierung der dortigen Burgen und Soldaten an. Dieses Einkommen konnte jedoch die tatsächlichen Kosten nicht decken und die türkische Offensive von I 432 verjagte den Deutschen Orden aus dem Severiner Land. ${ }^{4}$

Zur Genese der Bollwerksrethorik im östlichen Mitteleuropa an der Schwelle vom Mittelalter zur Frühen Neuzeit (Historische Studien 508), Husum 2015; L. Pósán, A Német Lovagrend története a 13. században [Die Geschichte des Deutschen Ordens im 13. Jahrhundert], Debrecen 1996, S. 21-43; ders., Ordinul Cavalerior Teutoni in Transilvania [Der Deutsche Orden in Siebenbürgen], Caiete de Antropologie Istorică 10 (2011), 2, S. 117-136; ders., Der Deutsche Orden im mittelalterlichen Ungarn, Ordines Militares Colloquia Torunensia Historica. Yearbook for the Study of the Military Orders 17 (2012), S. 123-136, hier: 123-130; ders., Die Münzprägung des Deutschen Ordens in Siebenbürgen, Acta Classica universitatis Scientiarum Debreceniensis 49 (2013), S. 73-79.

2 Urkundenbuch zur Geschichte der Deutschen in Siebenbürgen (weiter: UB), hrsg. v. F. Zimmermann, C. Werner, Bd. I: 1191-1342, Hermannstadt 1892, Nr. 51, 53, 55, 59, 61, 68, 91, 188, 196, 351; A. Armbruster, Nachspiel zur Geschichte des Deutschen Ordens im Burzenland, Revue Roumaine d'Histoire 18 (1979), S. 286-287.

3 F. Meltzer, Die Ostraumpolitik König Johanns von Böhmen. Ein Beitrag zur Ostraumfrage im 14. Jahrhundert (Beiträge zur mittelalterlichen und neueren Geschichte 12), Jena 1940, S. 46-49, 126-127; Ch. Krollmann, Politische Geschichte des Deutschen Ordens in Preußen, Königsberg 1932, S. 34-44, 59-60; G. Rhode, Die Ostgrenze Polens. Politische Entwicklung, kulturelle Bedeutung und geistige Auswirkung, Bd. I: Im Mittelalter bis zum Jahre 1401, Köln-Graz 1955, S. 173; H. Glassl, Ungarn im Mächtedreieck Ostmitteleuropas und der Kampf um das Zwischenland Schlesien, Ungarn-Jahrbuch 5 (1973) S. 16-49; J. K. Hoensch, Geschichte Polens, Stuttgart 1998, S. 45-48; J. K. Hoensch, Die Luxemburger. Eine spätmittelalterliche Dynastie gesamteuropäischer Bedeutung 1308-1437, Stuttgart 2000, S. 73-77.

4 E. Joachim, König Sigmund und der Deutsche Ritterorden in Ungarn 1429-1432, Mitteilungen des Instituts für Österreichische Geschichte 33 (1912), S. 108-115; F. Pesty, A szörényi bánság és Szörény vármegye története [Die Geschichte des Severiner Landes und des Komitats Severin], Bd. I, Budapest 1877, S. 37-40; Pósán, Der Deutsche Orden im mittelalterlichen Ungarn (wie Anm. 1), S. 132-136; L. Pósán, Sigismund und der Deutsche Orden, in: Das Zeitalter König 
Nach den Fiaskos im Mittelalter versuchte der Deutsche Orden drei Jahrhunderte später, zwischen 1702 und I 732 , noch einmal nach Ungarn zurückzukehren. Kaiser Leopold I. verkaufte dem Hochmeister Franz Ludwig von Pfalz-Neuburg (1694-1732) die Distrikte der Jazygen und Kumanen (ung. jászkun kerületek) zum ewigen Recht und unwiderruflich (iure perpetuo et irrevocabiliter) für 500000 rheinische Gulden.5 Die Habsburger Regierung betrachtete die von den Türken zurückeroberten ungarischen Gebiete als Güter, die auf Grund des ius armorum erobert worden waren, und versuchte sie zu verkaufen, um die militärischen Kosten, die um 1700 schon I 4 Millionen goldene Forint betrugen, decken zu können. ${ }^{6}$ Der Verkauf der Distrikte der Jazygen und Kumanen war ein Beispiel dafür. Die Rückkehr des Deutschen Ordens hatte aber auch eine Vorgeschichte. Nach der Säkularisation von Preußen ( 1525 ) wurde der Deutsche Orden in die Ordensprovinzen auf Habsburger Gebiet zurückgedrängt und verlor seinen bisherigen militärischen Charakter. Erst anderthalb Jahrhunderte später traf das Generalkapitel des Ordens I 662 in Wien die Entscheidung, für jährlich 60000-70000 rheinische Gulden ein Heer von 600 Personen aufzustellen. Dieses Regiment nahm auf Befehl des Hochmeisters Johann Caspar von Ampringen ( I664-I684) unter Leitung von Markgraf Ludwig Wilhelm von Baden ab I 664 am Krieg gegen die Türken in Ungarn teil, so auch an der siegreichen Schlacht von St. Gotthard (I. August I 664), wo viele Mitglieder des Ordens fielen. ${ }^{7}$ Nach der Aufdeckung der Wesselényi-Verschwörung gegen die Habsburger ( 1670 ) setzte der Kaiser und ungarische König Leopold I. die ständische Verfassung außer Kraft und berief Hochmeister Johann Caspar von Ampringen zum bevollmächtigten Gouverneur Ungarns. Der Tätigkeitsbereich des Guberniums mit drei ungarischen und drei österreichischen Räten bezog sich auf alle innenpolitischen Fragen,

Sigmunds in Ungarn und im Deutschen Reich, hrsg. v. T. Schmitt, P. Gunst, Debrecen 2000, S. 73-82.

5 Deutschordens-Zentralarchiv (weiter: DOZA) Wien, Ungarn Abteilung (weiter: U), 156/1, S. 23-244.

6 I. Wirth, A Jászkunság eladásának és visszaváltásának egyetemes történeti háttere [Der historische Hintergrund des Verkaufs und der Ablösung der Gebiete der Jazygen und Kumanen], in: Szolnok Megyei Múzeumok Évkönyve [Museumsjahrbuch des Komitats Szolnok], Szolnok 1981, S. 149-150.

7 K. Wieser, Acht Jahrbunderte Deutscher Orden (Quellen und Studien zur Geschichte des Deutschen Ordens 1), Bad Godesberg 1967, S. 416; H. H. Hoffmann, Der Staat des Deutschmeisters. Studien zu einer Geschichte des Deutschen Ordens im Heiligen Römischen Reich Deutscher Nation, München 1964, S. 267; B. Demel, Der Deutsche Orden seit 1525 - neue Aufgaben im Reich, in Österreich-Ungarn und seit 1929, in: Vergangenheit und Gegenwart der Ritterorden. Die Rezeption der Idee und die Wirklichkeit, hrsg. v. R. Czaja, J. Sarnowsky (Ordines Militares. Colloquia Torunensia Historica XI), Toruń 2001, S. 77-114, hier S. 77. 
aber seine wichtigste Aufgabe war, die Angelegenheiten der habsburgischen Armee zu regeln und diese zu versorgen. Der ehemalige Bischof von Wienerneustadt, der zum Kammerherrn der Ungarischen Kammer ernannte Leopold Karl von Kollonitsch, ein gehorsamer Unterstützer der absolutistischen Staatsverwaltung, schlug dem Hochmeister vor, dass der Deutsche Orden die Verteidigung einer südlichen Grenzburg übernehmen solle. ${ }^{8}$ Nach dem Ausbruch des von den Türken unterstützten Thököly-Aufstandes im Jahre I 678 schaffte Leopold I. I 68 I das Gubernium ab und musste auf dem Landtag in Ödenburg den ungarischen Ständen Zugeständnisse gewähren. Er willigte ein, dass der ungarische Adel wieder einen Palatin wählen konnte, der in Ungarn Stellvertreter des Königs war. Der Habsburgtreue Pál Eszterházy wurde der Palatin. Damit wurde das Gubernium überflüssig und der Plan, den Deutschen Orden in einer Grenzburg anzusiedeln, wurde von der Tagesordnung gestrichen. ${ }^{9}$ Leopold ernannte Hochmeister Ampringen I 682 zum Hauptkapitän von Schlesien. Dies bedeutete aber nicht, dass der Deutsche Orden nicht mehr an den Türkenkriegen teilnahm. I 683 kämpften die Ritter bei Wien gegen das Heer von Kara Mustafa. Nach dem Sieg in Wien entschloss sich die habsburgische Regierung, die von den Türken eroberten ungarischen Gebiete zurückzugewinnen. Das Regiment des Deutschen Ordens stand in diesen Kämpfen unter Befehl von Markgraf Ludwig Wilhelm von Baden und später von Herzog Eugen von Savoyen. Das Regiment war bei der Befreiung von Ofen (I686) und auch bei der Schlacht bei Senta (I I. September I 697) anwesend, die das Ende des Krieges mit sich brachte. Beim Sieg bei Senta spielte Graf Guidobald von Starheimberg, Landkomtur von Österreich, eine wichtige Rolle. ${ }^{10}$

Während des Großen Türkenkrieges, der I 699 zu Ende ging, wurden die Distrikte der Jazygen und Kumanen wieder unter die Oberhoheit der ungarischen Krone gestellt. Leopold Karl von Kollonitsch, Kammerherr der Ungarischen Kammer, ordnete noch in demselben Jahr an, die demografischen und die wirtschaftlichen Verhältnisse dieses Gebietes zu untersuchen, um den Verkauf des Gebietes vorzubereiten. Mit dieser Aufgabe beauftragte er Franz Christoph Johann Pentz, den Präfekten der Erlauer Kammer. Pentz konnte kein Ungarisch

8 DOZA, U 159/1, S. 107.

9 I. Gonda, E. Niederhauser, A Habsburgok [Die Habsburger], Budapest 1987, S. 91; R. Á. Várkonyi, A Királyi Magyarország 1541-1686 [Das königliche Ungarn 1541-1686], Budapest 1999, S. 125-131; J. Kiss, Das erste Jahrzehnt des Deutschen Ordens in Ungarn (1702-1712), Acta Historica Akademiae Scientiarum Hungariae 30 (1984), 1-2, S. 3-44, hier S. 23.

10 Demel (wie Anm. 7), S. 78; H. M. Kakucska, Orczy Lörinc forditástöredéke II. Rákóczi Ferenc fejedelem „Emlékiratok” cimü munkájából [Übersetzungsfragment von Lörincz Orczy in den Erinnerungen von Fürst Ferenc Rákóczi II.], Erdélyi Múzeum Egyesület 68 (2007), 3-4, S. 180-186, hier S. 181. 
und war nie in diesem Gebiet gewesen. Darum wandte er sich an Ferenc Sötér, den Vizegespan des Komitats Pest und Vizekapitän des Palatins der Distrikte der Jazygen und Kumanen. ${ }^{11}$ Auf Grund des Petz-Berichtes ${ }^{12}$ stellte die Wiener Regierung fest, dass das Gebiet für 500000 goldene Forint verkauft werden könne. ${ }^{13}$ Die dort lebenden Leute wurden im Bericht als Leibeigene bezeichnet, obwohl dieses Gebiet seit dem Mittelalter seine eigenen Privilegien genoss, unmittelbar der Verwaltung des ungarischen Königs unterstand und nie unter die Gerichtsbarkeit eines Landsherrn gefallen war. Die ungarischen Könige regierten hier durch den Palatin. Die Bewohner des Gebiets zahlten dem Palatin Zensus und mussten nur Militärdienst, aber keinen Frondienst leisten. Der Palatin war der Hauptkapitän und Hauptrichter der Jazygen und Kumanen. An die Spitze der Regionen Nagykunság, Kiskunság und Jászság wurde je ein Kapitän gewählt, der dort als Beamter des Palatins fungierte. ${ }^{14}$ Die Zusammenschreibung der Kammer von 1699 nannte die Jazygen und Kumanen Leibeigene, womit ihre Privilegien bezweifelt wurden. Im Sommer I 699 wurde in Wien die Entscheidung getroffen, die Distrikte der Jazygen und Kumanen zu verkaufen. Es wurde damals noch nicht mit dem Deutschen Orden als potentiellem Käufer gerechnet. Leopold Karl von Kollonitsch traf am 9. April I70 I im Namen des Kaisers die Entscheidung, dass die katholische Kirche alle Güter, die sie wegen der türkischen Eroberung oder wegen der Reformation verloren hatte, zurückbekommen sollte. Auf Grund dieser Entscheidung warf der Deutsche Orden im April und Juni I 70 I die Wiedergabe seiner ehemaligen Gebiete in Burzenland auf. ${ }^{\text {is }}$ Der Hochmeister beauftragte den Befehlshaber der Truppen des Ordens in Siebenbürgen, Graf Damian Hugo von Virmond, am I 4. Juli I 70 I, die Situation von Burzenland hinsichtlich der Frage zu untersuchen, ob es dort Beweise für die Grundherrschaft des Ordens gäbe bzw. ob

11 J. Illéssy, A Jász-Kunság eladása a Német Lovagrendnek [Der Verkauf der Gebiete der Jazygen und Kumanen an den Deutschen Orden], Századok 39 (1905), S. 22-39, hier S. 24-26; G. Cseh, A Nagykunság leírása az 1699. évi Pentz-féle összeírásban [Die Beschreibung von Nagykunság in der Zusammenschreibung von Pentz von 1699], in: A Jász-Nagykun-Szolnok Megyei Levéltár Évkönyve [Jahrbuch des Archivs des Komitats Jász-Nagykun-Szolnok], Bd. 17, hrsg. v. M. Zádorné Zsoldos, Szolnok 2002, S. 195-220, hier S. 195.

12 Magyar Országos Levéltár (weiter: OL), Urbaria et Conscriptiones (weiter: UC) 71:4 - Conscriptio Jassigum et tam Maiorum quam minorum Cumanorum.

13 Wirth (wie Anm. 6), S. 149.

14 G. Bagi, A Jászkun Kerület társadalma a redempciótól a polgári forradalomig, 1745-1848 [Die Gesellschaft der Distrikte der Jazygen und Kumanen von der Redemption bis zur bürgerlichen Revolution, 1745-1848], Szolnok 1995, S. 16-21; J. Kiss, A Jászkun Kerület parasztsága a Német Lovagrend földesúri hatósága idején (1702-1731) [Das Bauerntum der Distrikte der Jazygen und Kumanen während der landesherrlichen Oberhoheit des Deutschen Ordens (1702-1731)], Budapest 1979, S. 33.

15 DOZA, U 159/1, S. 1-65. 
die Erinnerung an die Grundherrschaft dort fortlebe. ${ }^{16}$ Der Graf untersuchte diese Frage ein halbes Jahr lang, fand aber keine Beweise für die anderthalb Jahrzehnte lange Grundherrschaft des Ordens in Burzenland. Erst nach dieser Untersuchung beschäftigte sich der Orden mit dem Gebiet der Jazygen und Kumanen. Leopold Karl von Kollonitsch bot dem Orden den Kauf dieses Gebietes anstelle des Burzenlandes an und schlug auch vor, dass der Orden die Verteidigung zweier südlicher Grenzburgen, Essegg und Slawonski Brod, übernehmen könne, wofür der Fiskus ihm jährlich 25000 Gulden zahlen würde. Dabei, dass das größte Kammergut des Landes dem Deutschen Orden zum Kauf angeboten wurde, soll auch die Tatsache eine Rolle gespielt haben, dass Hochmeister Ludwig von Pfalz-Neuburg der Schwager von Kaiser Leopold I. war. Durch die Unterstützung des Kaisers wurde er schon 1683 Bischof von Breslau und zwei Jahre später Hauptkapitän von Schlesien, so dass er die wichtigsten kirchlichen und weltlichen Funktionen von Schlesien in einer Hand vereinigen konnte. ${ }^{17}$ Im Sinne des Vertrags vom 22. März 1702 kaufte der Deutsche Orden für 500000 goldene Forint die Distrikte der Jazygen und Kumanen. ${ }^{18}$ Der Hofkriegsrat erlaubte ihm aber nicht, die Verteidigung zweier Grenzburgen zu übernehmen und dafür vom Fiskus jährlich 25000 Forint zu erhalten. ${ }^{19}$ Am Kaufgeschäft nahm auch Leopold Karl von Kollonitsch teil. Er zahlte nämlich die Hälfte des Preises, so dass der Orden nur 250000 Forint zahlen musste. $^{20}$

Laut der Kammeruntersuchung von 1699 hatten die vom Orden gekauften Gebiete während des Türkenkrieges großen Schaden erlitten: Während es im I 6. Jahrhundert hier noch 73 Dörfer und 4 Marktflecken gab, waren es nach dem Frieden von Karlowitz (1699), um die Jahrhundertwende des 17.- I 8. Jahrhunderts, nur noch 17 Dörfer und 2 Marktflecken. 50\% der Marktflecken und 77\% der Dörfer waren also vernichtet. ${ }^{21}$ In die Zentren der drei Distrikte schickte der Orden Provisoren: Ins Zentrum von Kiskunság nach Kiskunhalas wurde Baron Tobias Leistner, nach Karcagújszállás im Distrikt Nagykunság Konrad von Reinach, und nach Jászberény im Distrikt Jászság, das den geringsten Schaden erlitten hatte, Baron Heinrich von Kaganeck, Komtur von Frankfurt, geschickt. Statt des Palatins

16 DOZA, U 158/1, S. 4-10.

17 B. Demel, Franz Ludwig von Pfalz-Neuburg als Hoch-und Deutschmeister (1694-1732) und Bischof von Breslau (1683-1732), Jahrbuch der schlesischen Friedrich-Wilhelms-Universität zu Breslau 36/37 (1995/1996), S. 93-150; D. Galewski, Das Mäzenatentum des Fürstbischofs von Breslau Franz Ludwig von Pfalz-Neuburg (1683-1732), Jahrbuch des Wissenschaftlichen Zentrums der Polnischen Akademie der Wissenschaften in Wien 2 (2009) [2011], S. 55-66.

18 DOZA, U 156/1, S. 233-244.

19 DOZA, U 172/5.

20 DOZA, U 172/4.

21 OL, UC 71:4. 
waren nun sie, unterstützt vom Heer des Ordens, die Erbgerichtsherren. Auch nach dem Verkauf von 1702 blieben die autonomen Institutionen auf den unteren und mittleren Stufen der Verwaltung bestehen. Die Richter und die Geschworenen der Dörfer und Marktflecken wurden durch die örtliche Bevölkerung, die Kapitäne der Distrikte durch die Abgeordneten der Dörfer oder Städte gewählt. Infolge dessen blieben die Bodennutzung und die gesellschaftlichen und wirtschaftlichen Verhältnisse unverändert. Die Distrikte der Jazygen und Kumanen bezahlten die Steuer nicht nach den Einzelhöfen, sondern als Gemeinschaft, und sie zahlten nur die Grundpacht (ung. árenda). ${ }^{22}$ Eigene Grundherrschaften konnte der Orden nicht zustande bringen. Nach der Inbesitznahme von 1703 besuchte Provisor Heinrich von Kaganeck im Auftrag des Hochmeisters die Distrikte und machte über seine Erfahrungen Aufzeichnungen. ${ }^{23}$ Gemäß Kaufvertrag bekam der Orden den Titel des ewigen Herrn von Jászkunság. Damit ging die Oberhoheit des Palatins über die Distrikte zuende, die seit dem Mittelalter bestanden hatte. Palatin Eszterházy und die ungarischen Stände protestierten gegen den Verkauf. Sie meinten, dass er unrechtmäßig wäre, weil der Landtag keine Einwilligung dazu gegeben hätte, und betrachteten den Verkauf als Missachtung der alten Privilegien. Die Leibeigenschaft trug dazu bei, dass sich die Jazygen und Kumanen dem antihabsburgischen Aufstand vom Mai 1703 von Ferenc Rákóczi II., einem der mächtigsten ungarischen Aristokraten, anschlossen, um ihre alten Privilegien zurückzubekommen. Baron Kaganeck teilte dem Hochmeister am 3 I. Mai und am 22. August 1703 mit, dass die Jazygen in die Truppen der Kuruzen eintraten. ${ }^{24}$ Baron Reinach schrieb am 28. August, dass sich die Hälfte der wehrhaften Bevölkerung den Rebellierenden angeschlossen habe. ${ }^{25}$ Kaum ein Jahr nach dem Verkauf verlor der Deutsche Orden die Gebiete der Jazygen und Kumanen. Er konnte keine Hilfe von Wien erwarten, weil die Österreicher im Westen gegen Frankreich Krieg führten, und er ließ in Ungarn wenige Truppen stationieren. Daher konnten die Kuruzen immer größere Gebiete unter ihre Aufsicht ziehen. Die Geschehnisse in Ungarn trugen dazu bei, dass der Orden in der Nähe von Schlesien, in Mähren wo er schon seit I62 I große Güter (Freudenthal, Eulenberg) ${ }^{26}$ hatte und diese

22 Kiss, A Jászkun Kerület parasztsága (wie Anm. 14), S. 33, 97-99.

23 DOZA, U 156/1, S. 1-588. Diarium und Berichte der ersten Generalvisitation der Jazygerund Kumanendistrikte durch Baron von Kogeneck; J. Illéssy, Kaganeck utinaplója a Jászságról 1703-ban, Nagy-Kunság XXII/31 (1902), S. 1-2; XXVII/32 (1902), S. 1-3.

24 DOZA, U 163/2, S. 359-366, 411-412.

25 DOZA, U 168/1.

26 F. Spurny, Letzter Soldatenrubm der Deutschordensfeste Eulenberg, in: Acht Jahrhunderte Deutscher Orden in Einzeldarstellungen. Festschrift für Hochmeister P. Dr. Marian Tumler OT. zum 80. Geburtstag, hrsg. v. K. Wieser (Quellen und Studien zur Geschichte des Deutschen Ordens 1), Bad Godesberg 1967, S. 395-408. hier S. 395. 
I 696 durch neue Gebiete (Bouzov, Rotülhutten) vergrößerte - die königliche Burg Nemlau, die am 8. Juni 1703 der Stadt Breslau verpfändet worden war, mit dem zu ihr gehörenden Gut für I I 0 oo० rheinische Gulden und am 2. Juli Unterlagendorf neben dem Gut von Eulenberg für 95000 Gulden kaufte. ${ }^{27}$ Es scheint, dass der Deutsche Orden, der seine Güter in Ungarn verloren hatte, versuchte, in den Erbländern in Mähren einen größeren Güterkomplex zusammen zu bringen. Er wollte sich aber auch nicht damit zufrieden geben, 250000 Forint für nichts gezahlt zu haben. Er versuchte daher zu erreichen, dass kaiserliche Truppen in die Gebiete der Jazygen und Kumanen einzogen. Der Hofkriegsrat traf im August 1703 die Entscheidung, ein Kontingent aus den Garnisonen von Peterwardein, Slawonski Brod und Essegg in die Distrikte der Jazygen und Kumanen abzukommandieren. Konrad von Reinach schrieb dem Hochmeister in einem Brief vom I I. Oktober 1703, dass die kaiserlichen Truppen die Region Kiskunság verwüstet hätten. Aus Szabadszállás hätten sie 50 Pferde, 2700 Schafe und aus Fülöpszállás 45 Pferde und 6000 Schafe weggeführt. Von den Widerstand leistenden Bewohnern wurden 50 getötet. ${ }^{28}$ Die Kuruzen besiegten diese kaiserlichen Truppen am 5. Oktober 1703 bei Kiskunhalas. ${ }^{29}$ Der Leiter der aufständischen Kuruzen, Fürst Rákóczi, erklärte am 27. Oktober 1703 den landesherrlichen Status des Ordens in den Distrikten der Jazygen und Kumanen für unrechtmäßig und ernannte statt Palatin Eszterházy, der den Habsburgern treu blieb, seinen Hofmarschall Ádám Vay zum Hauptkapitän der Jazygen und Kumanen..$^{\circ}$ Der Orden erlitt zu dieser Zeit auch im Westen großen Schaden, weil die französischen Truppen, die nach Osten drangen, viele Güter des Ordens in Frankreich verwüsteten. ${ }^{31} \mathrm{Im}$ Sommer I 704 brachen wieder kaiserliche Truppen in die Distrikte der Jazygen und Kumanen ein, wo sie die Siedlungen Karcagújszállás, Kunmadaras und Kunhegyes niederbrannten. Mehr als 2000 Soldaten der Jazygen und Kumanen kämpften damals an der Seite der Kuruzen..$^{22}$ Der Landtag der Kuruzen deklarierte im September 1705 die Freiheit der Distrikte der Jazygen und Kumanen, aber am 24. September zog erneut eine kaiserliche Truppe von 25000 Soldaten unter Lei-

27 B. Demel, Der Deutsche Orden in Mähren und Schlesien, Jahrbuch der schlesischen FriedrichWilhelm-Universität zu Breslau 32 (1991), S. 29-68, hier S. 56.

28 DOZA, U 161/1.

29 T. Esze, A Tisza-vonal védelme a kurucok ellen 1703-ban [Die Verteidigung der Theißlinie gegen die Kuruzen im Jahre 1703], in: Rákóczi-tanulmányok [Rákóczistudien], hrsg. v. B. Köpeczi, L. Hopp, R. Á. Várkonyi, Budapest 1980, S. 597-681, hier 630-634.

30 OL, Károlyi Lt P 1501:1

31 Kiss, Das erste Jahrzehnt des Deutschen Ordens (wie Anm. 9), S. 36; J. Kalmár, A Spanyol örökösödési háború [Der spanische Erbfolgekrieg], in: A kora újkor története [Geschichte der frühen Neuzeit], hrsg. v. J. Poór, Budapest 2009, S. 70-79.

32 OL, UC 156-110:39 
tung von General Ludwig Herbewille zusammen mit Kontingenten des Deutschen Ordens unter Leitung von Baron Wachtendeuck in die Region Kiskunság ein. Der Befehlshaber des Ordens machte den Jazygen und Kumanen klar, dass sie unter der Grundherrschaft des Ordens stünden und die Distrikte Gebiete des Ordens wären. Nachdem sich das Heer von Herbewille mit Lebensmitteln und Futter bevorratet hatte, zog es weiter nach Siebenbürgen, um die dortigen Truppen zu verstärken. Die Truppen des Ordens gingen auch mit Herbewille, wurden aber im nächsten Sommer zurückkommandiert, um Wien zu verteidigen. ${ }^{33} \mathrm{Im}$ September I 706 drang Rabutin, General der siebenbürgischen kaiserlichen Truppen, in die Region der Theiß ein und machte monatelang auf dem Gebiet der Jazygen und Kumanen Station, wo er fast alle Siedlungen niederbrannte. Der größte Teil der Bevölkerung flüchtete in das Komitat Szabolcs, das damals schon unter der Aufsicht der Kuruzen stand. Später siedelte Fürst Rákóczi diese Leute auf seinem eigenen Gut in der Nähe von Rakamaz an. Nachdem die Anhänger von Rákóczi im Mai 1707 auf dem Landtag von Ónod die Inthronisierung der Habsburger bekanntgemacht und die Steuerzahlung auch auf den Adel ausgeweitet hatten, schwur der gemäßigte Teil des Adels dem Kaiser wieder Treue. Palatin Eszterházy nutzte diese politische Situation und berief 1708 im Auftrag des Kaisers einen Landtag in Pressburg ein. ${ }^{34}$ In Anbetracht der Geschehnisse versuchte Hochmeister Franz Ludwig mit den habsburgisch gesinnten ungarischen Ständen, die Rechtmäßigkeit des Kaufs der Distrikte der Jazygen und Kumanen bestätigen zu lassen. Mit dieser Aufgabe wurde am 26. Januar 1708 der Landkomtur von Österreich Baron Christoph Heinrich von Kyau beauftragt. ${ }^{35}$ Im Sommer 1708 verwüsteten die kaiserlichen Truppen wieder die Gebiete der Jazygen und Kumanen. ${ }^{36}$ Am 3. August 1708 erlitten die Kuruzen bei Trencsén eine schwere Niederlage. Neben der Verwüstung stellte auch die Pest einen großen Schlag dar. Die Epidemie dauert vom Herbst 1708 bis Ende 1710 und erwies sich als sehr

33 Kiss, Das erste Jahrzehnt des Deutschen Ordens (wie Anm. 9), S. 38.

34 N. I. Kiss, Az 1707. évi Rákóczi-féle dicalis conscriptio [Dicalis conscription von Rákóczi von 1717], in: Rákóczi-tanulmányok (wie Anm. 29), S. 87-112; I. Bánkúti, A kuruc függetlenségi háború gazdasági problémái 1703-1711 [Die finanziellen Probleme des Unabhängigkeitskrieges der Kuruzen zwischen 1703 und 1711], Budapest 1991, S. 105; J. Bérenger, K. Kecskeméti, Országgyülés és parlamenti élet Magyarországon 1608-1918 [Landtag und die Tätigkeit des Landtags in Ungarn zwischen 1608 und 1918], Budapest 2008, S. 130-138; M. I. Szijártó, A diéta. A magyar rendek és az országgyülés 1708-1792 [Der Landtag. Die ungarischen Stände und der Landtag zwischen 1708-1792], Budapest 2005, S. 58.

35 DOZA, U 170/1.

36 Kiss, Das erste Jahrzehnt des Deutschen Ordens (wie Anm. 9), S. 40. 
verheerend. ${ }^{37}$ Im Januar 17 Io erlitten die Kuruzen bei Romhány wieder eine schwere Niederlage und mussten sich vor den kaiserlichen Truppen zurückziehen. Wien konnte eindeutig von dieser militärischen Situation profitieren, woraus auch der Deutsche Orden neue Hoffnung schöpfte. Johann Christoph Reisweg ab Ehrenfeld, Präfekt des Ordens in Ofen (Ofen blieb während des Rákóczi Aufstandes immer in den Händen des Kaisers), forderte die Leiter der Gebiete der Jazygen und Kumanen in einem Brief vom I 6. April I 7 I 0 auf, sich dem Deutschen Orden zu unterwerfen. Am I 9. April teilte er den dort Lebenden mit, dass er vom Hochmeister beauftragt worden sei, die Leute, die wegen des Krieges wegflüchteten, zurückzusiedeln. Er machte auch klar, dass die kaiserlichen Truppen auftreten würden, wenn sie sich gegen den Deutschen Orden, den gesetzlichen Erbherrn, auflehnten oder ihm nicht gehorsam wären. ${ }^{38} \mathrm{Im}$ Sommer $17 \mathrm{I}$ o zogen die kaiserlichen Truppen gegen Neuhäusel, die am besten verstärkte Burg der Kuruzen.. ${ }^{39}$ An der Belagerung nahm auch ein Regiment des Ordens teil. Die Burg kapitulierte am 24. September. So wurde für die habsburgischen Truppen der Weg in die Region zwischen der Donau und der Theiß, also auch in die Gebiete der Jazygen und Kumanen, eröffnet. Diese Gebiete gerieten im Oktober tatsächlich unter die landesherrliche Kontrolle des Ordens. Der Hochmeister beabsichtigte schon vorher die Wiedereroberung der ungarischen Gebiete, denn er beauftragte im Mai I 7 I 0 Baron von Kyau, Landkomtur von Österreich, damit, neue Regelungen für die Verwaltung und Besteuerung der Distrikte der Jazygen und Kumanen vorzubereiten..$^{40}$ Nach dem Einzug der kaiserlichen Truppen in Jászkunság begann der Präfekt des Ordens von Ofen Reisweg ab Ehrenfeld die Situation einzuschätzen. Die drei Provisoren des Ordens notierten Zahlen von 804 Bauern, 490 Dienern, 872 Frauen und I 49 I Jungen und Mädchen älter als is Jahre. Die Leute, die aus den Distrikten geflüchtet waren, kehrten erst im nächsten Jahr aus der Umgebung von Rakamaz zurück. Unterstützt von den kaiserlichen und ritterlichen Truppen versuchte Ehrenfeld mit Gewalt, die in den Jahre 1704-1710 ausgefallenen landesherrlichen Steuern einzutreiben. Dieser Plan erwies sich aber wegen der Verwüstung durch den langen Krieg als nicht realisierbar und führte zu breiter Empörung. Die Jazygen und Kumanen wandten sich mit ihren Beschwerden an

\footnotetext{
37 P. Öri, A pestisjárványok demográfiai következménye a 17-18. századi Magyarországon [Die demografischen Folgen der Pestepidemien im 17-18. Jabrbundert in Ungarn], in: Történeti Demográfiai Évkönyv 2005 [Jahrbuch für historische Demografie, 2005], Budapest 2006, S. 115-162, hier S. 128-129.

38 Kiss, Das erste Jahrzehnt des Deutschen Ordens (wie Anm. 9), S. 41.

39 I. Bánkúti, A szatmári béke [Der Frieden von Szatmár], Budapest 1981, S. 28-30.

40 DOZA, U 160/L 67-74; U 170/1 Acta Miscellanea.
} 
den Palatin und den Hochmeister. ${ }^{41}$ Dies führte dazu, dass der Hochmeister Ehrenfeld in einem Brief vom 8. Oktober I I I I befahl, dass er von den in den vorherigen Jahren ausgefallenen landesherrlichen Steuern wegen der Verwüstungen absehen solle. ${ }^{42}$ Aber der Orden bestimmte seine Steuerwünsche für jedes Jahr in einer immer größeren Summe: Im Jahre I7 I 2 erwartete er I I 550 und I 7 I 3 schon 12950 Gulden. ${ }^{43}$ Demzufolge beklagten sich die Jazygen und Kumanen wieder in Wien und in Breslau bei der Leitung des Ordens, beim ungarischen Palatin und beim Wiener Hof. Diese Beschwerden mussten ernst genommen werden, weil der Kaiser im Frieden von Szatmár (29. April i 7 I I), der den Aufstand abschloss, den Rebellierenden nicht nur eine Generalamnestie, sondern auch die Unverletzbarkeit der Privilegien und Rechte der ungarischen Stände zugesichert hatte und versprochen hatte, mit zivilrechtlichen und militärischen Mitteln gegen diejenigen vorzugehen, die diese Rechte schänden. ${ }^{44}$ Die Rechtmäßigkeit des Kaufs der Gebiete der Jazygen und Kumanen blieb also weiterhin unsicher, der Hochmeister wollte aber die Situation des Ordens in Ungarn nicht mit Beschwerden über die Unrechtmäßigkeit erschweren. Nach dem Tod von Johann Christoph Reisweg ab Ehrenfeld (im April 17 I 4) beauftragte er den Landkomtur von Österreich Baron Kyan mit dem Besuch der Gebiete der Jazygen und Kumanen und mit der Untersuchung der Beschwerden und der Situation. Um die Gemüter zu beruhigen wurden auch Beamte des Ordens, die mit Ehrenfeld zusammengearbeitet hatten, zurückgerufen. An die Spitze der Gebiete der Jazygen und Kumanen wurdederungarische AdligeIstván Orczy, Vizegespan des KomitatsHeves-Külső-Szolnok, gesetzt und zum Hauptinspektor des Ordens ernannt. Baron Kyau kam am 26. August 1714 in Jászberény an und besuchte bis zum 5. September zusammen mit István Orczy die Siedlungen der Jazygen und Kumanen. Zehn Tage später schickte er ausführliche Vorschläge für Maßnahmen an den Hochmeister. Nach seiner Meinung konnte die schwere Besteuerung der Jazygen und Kumanen dazu führen, dass die Bevölkerung in großer Anzahl in die Nachbarkommitate übersiedelte, weil die Landsherren dort nach den Türken- und Kuruzenkriegen versuchen würden, mit großen Ermäßigungen Siedler anzulocken. ${ }^{45}$ Der Landkomtur brachte auch die Idee zur Sprache, die Gebiete der Jazygen und Kumanen gegen Güter

41 G. Cseh, Kyau lovagrendi landkomtur 1714. évi jelentése a Jászkunságról [Der Bericht des Landkomturs Kyau über das Gebiet der Jazygen und Kumanen von 1714], in: A Jász-Nagykun-Szolnok Megyei Levéltár Évkönyve [Jahrbuch des Archivs des Komitats Jász-Nagykun-Szolnok], Bd. 19, hrsg. v. M. Zádorné Zsoldos, Szolnok 2004, S. 263-279, hier S. 264.

42 DOZA, U 162/1, S. 38-46.

43 DOZA, U 167/3. és 155/3, S. 174.

44 Bánkúti, A szatmári béke (wie Anm. 39), S. 113-116.

45 Cseh, Kyau lovagrendi landkomtur (wie Anm. 41), S. 264-268. 
in Böhmen oder in Mähren zu tauschen. ${ }^{46}$ Es schien, dass sich die Politik des Ordens gegenüber den Jazygen und Kumanen nach dem Tod von Ehrenfeld veränderte. Hierzu trug auch die Tatsache bei, dass der neue Kaiser Karl VI. (als ungarischer König Karl III.), der I 7 I 2 den Thron bestieg, einen Landtag einberief, der bis i 7 I 5 tagte, um Gesetze zu erlassen, die zur Versöhnung nach dem Rákóczi-Aufstand dienten. ${ }^{47}$ Im Herbst 17 I 4 wurden die Fragen bezüglich der Gebiete der Jazygen und Kumanen und der Rechtmäßigkeit von deren Verkauf in die Tagesordnung aufgenommen. Die hier verabschiedeten Gesetze unterzeichnete der König am I5. Juni 1715. Damit wurde der Gesetzesartikel 34 über die Jazygen und Kumanen wirksam, der deklarierte, dass der Verkauf im Jahre 1702 rechtswidrig gewesen sei und diese Gebiete ihre Privilegien zurückgewinnen könnten, indem der Deutsche Orden den für die Gebiete gezahlten Preis zurückbekomme. Das Gesetz erklärte die Gebiete für verpfändet, aber allzeit auslösbar. Die Rückzahlung der Kosten nahmen teils der Fiskus, teils die Stände auf sich. Für die Rückzahlung sah das Gesetz drei Jahre vor und ordnete an, dass diese Distrikte nach der Auslösung wieder Krongüter werden, die unter der Aufsicht des Palatins stehen. ${ }^{48}$

Nach drei Jahren konnte aber wegen der erneuten Türkenkriege zwischen I 7 I 6-I 7 I 8 niemand den Orden bezahlen, weil man das Geld für die militärischen Kosten brauchte. Zehn Regimente der habsburgischen Truppen unter Befehl von Eugen von Savoyen zogen im Mai 17 I 6 durch den Distrikt Nagykunság zur Belagerung von Temeschwar und machten drei Wochen lang auf dem Gebiet der Jazygen und Kumanen Station. Der Beamte des Ordens István Orczy schrieb in einem Bericht vom Juni 17 I 6, dass die Soldaten sehr großen Schaden verursacht hätten. ${ }^{49}$ Die Truppen des Deutschen Ordens nahmen auch am Krieg teil. In der Schlacht von Belgrad am I 6. August I 7 I 7 führte Reichsgraf Joseph Philipp von Harrach zu Rohrau, Landkomtur von Österreich, einen Flügel des kaiserlichen Heers. ${ }^{5 \circ}$ Trotz seiner militärischen Teilnahme konnte der Deutsche Orden nach dem Frieden von Passarowitz ( 17 I 8), der die Türkenkriege beendete, kein neues Ergebnis in der Sache der Distrikte der Jazygen und Kumanen erreichen. Wegen der Kriegskosten hatte er keine Chance vom Fiskus und von den ungarischen Ständen 500000 goldene Forint zu bekommen, aber wegen des Gesetzesartikels 34 von 17 I 5 hatte er auch keine Möglichkeit, seine Ideen einer landesherrlichen Wirtschaft zu verwirklichen. König Karl machte sich um den fehlenden männlichen Erben mehr

46 DOZA, U 166/1, S. 1-394.

47 Bérenger, Kecskeméti (wie Anm. 34), S. 143-154.

48 DOZA, U 172/1.

49 DOZA, U 155/3.

50 Demel, Der Deutsche Orden seit 1525 (wie Anm. 7), S. 78. 
Sorgen und versuchte wegen der Anerkennung der Erbfolge seiner Tochter mit den ungarischen Ständen zusammenzuarbeiten und ihre Rechte und Privilegien zu bewahren. Als Resultat nahm der Landtag von 1722-1723 die weibliche Erbfolge der Habsburger, die sog. Pragmatische Sanktion, an..$^{\text {st }}$ Es wurde sowohl dem Orden als auch den gewählten Distriktvorstehern klar, dass weder der ungarische Landtag noch der Wiener Hof das Geld für die Ablösung der Distrikte zusammensammeln kann. Vor allem István Orczy, Hauptinspektor der Distrikte, und die örtlichen Vorsteher wollten ihre ehemaligen Privilegien zurückbekommen. Deswegen suchten sie in Pressburg und in Wien Unterstützer für die sog. Redemption (Selbstablösung), die die einzige legitime Möglichkeit einer Ablösung der Feudallasten darstellte. Nach der Genehmigung des Palatins erhöhten sie die Steuern der Jazygen und Kumanen, um Geld für die Ablösung zu sammeln, aber verheimlichten dies sowohl der örtlichen Bevölkerung als auch dem Deutschen Orden. Für die erhöhte Steuer wurde dem Landesherrn, also dem Deutschen Orden, die Schuld zugewiesen, so dass sich die Leute wegen der größeren Last ans Gericht und an den Hochmeister wandten. Ferenc Nagy, Bauer aus Jászberény, reichte beim Gericht eine Klage gegen den Magistrat von Jászberény ein, weil der Magistrat neben der Steuer des Deutschen Ordens die Bevölkerung noch durch andere Steuern belastet und die Vorsteher einen Teil der Steuern hinterzogen hätten. Der Magistrat konnte nicht sagen, dass er das Geld für die Redemption brauchte, und versuchte die Verantwortung auf die Steuereinnehmer des Ordens und die Inspektoren abzuschieben..$^{22}$ Die Unzufriedenheit war so groß, dass 1726 noch ein Aufstand in Jászság ausbrach. ${ }^{53}$ Dieser Aufstand war für den Hochmeister der Tropfen, der das Fass zum Überlaufen brachte: Er hatte von den Beschwerden, dem politischen Tauziehen, der Infragestellung seines Eigentumsrechtes, das das Gesetz von 1715 garantierte, genug und versuchte möglichst ohne finanziellen Schaden die Distrikte loszuwerden. Hochmeister Franz Ludwig dachte zuerst an die Idee von Baron Kyau von I 7 I 4, der einen Gütertausch vorgeschlagen hatte. Er wollte mit Graf Zinzendorf die Distrikte der Jazygen und Kumanen gegen die Güter in Karlswald tauschen. Nach zweijährigen Verhandlungen scheiterte der Plan jedoch Anfang 173 1. ${ }^{54}$ Parallel zu den Verhandlungen über den Gütertausch sprach die Führung des Ordens auch über den Verkauf der Distrikte. Das Invalidenhaus zu Pest für verwundete oder invalide Soldaten des Türkenkrieges, gegründet aus dem

51 J. Barta, A kétfejü sas árnyékában [Im Schatten des Doppeladlers], Budapest 1984, S. 94; J. Barta, A 18. század története [Die Geschichte des 18. Jahrhunderts], Budapest 2000, S. 35; Bérenger, Kecskeméti (wie Anm. 34), S. 154-159.

52 DOZA, U 155/2, S. 1-30.

53 DOZA, U 162/1, S. 104-230.

54 DOZA, U 171, 172/3. 
Nachlass des Graner Erzbischofs György Széchenyi (I605-I695) von I7 I 6, kam mit einem ernsthaften Kaufvorhaben. Karl III. genehmigte die Kaufpläne, und so bezahlte das Invalidenhaus den ehemaligen Preis von 500000 Forint, und der Hochmeister übertrug das Eigentumsrecht an den Distrikten am 8. März I73 I dem Invalidenhaus. Auf Grund des Gesetzartikels 34 von 17 I 5 brachte dieser Kauf jedoch nur das Übereignen des Pfandrechtes und keinen tatsächlichen Erwerb von Eigentum mit sich. Die Lage der Distrikte der Jazygen und Kumanen änderte sich nicht wesentlich. Sie konnten auch weiterhin nur mit Redemption die landesherrliche Oberhoheit loswerden.55 Der Verkauf wurde erst i74 I durch den Landtag genehmigt, weil dieser erst in dem Jahr einberufen wurde. Auch der neue Landesherr versuchte die Steuern zu erhöhen und Gehöfte zu erbauen, um das Geld, das er für die Distrikte ausgab, zurückzubekommen. Das ist ihm aber, ähnlich wie dem Orden, nicht gelungen. ${ }^{56}$ Im Jahre 1745 konnten sich die Jazygen und Kumanen von der landesherrlichen Oberhoheit lösen. Die Urkunde der Königin Maria Theresia vom 6. Mai 1745 (Confirmatio Privilegiorum pro Districtibus Jazigum et Cumanorum) stellte die alten Privilegien der Jazygen und Kumanen wieder her und dazu bekamen sie noch den Blutbann. ${ }^{57}$

\section{QUELLEN- UND LITERATURVERZEICHNISS}

Zimmermann, Franz., Werner, Carl., edit. "Urkundenbuch zur Geschichte der Deutschen in Siebenbürgen." Vol. I: IIII-1342. Hermannstadt: In Kommission bei Franz Michaelis, I 892.

Adriányi, Gabriel. “Zur Geschichte des Deutschen Ritterordens in Siebenbürgen.” Ungarn-Jahrbuch 3 (1971): 9-22.

Armbruster, Adolf. "Nachspiel zur Geschichte des Deutschen Ordens im Burzenland." Revue Roumaine d'Histoire I 8 (1979): 286-287.

Bagi, Gábor. A Jászkun Kerület társadalma a redempciótól a polgári forradalomig, 1745-I848. Szolnok: Damjanich János Múzeum, I 995.

55 Kakucska (wie Anm. 10), S. 182.

56 J. Kiss, A Pesti Invalidus Ház jászkunsági földesurasága, 1731-1745 [Die landherrschaftliche Oberhoheit des Ofener Invalidenhauses auf dem Gebiet der Jazygen und Kumanen], Budapest 1992.

57 OL, A 57 - Libri Regii, Bd. 40; I. Soós, A jászkun redemptio 1745 [Die Redemption der Jazygen und Kumanen 1745], Budapest 2006. 
Bánkúti, Imre. A kuruc függetlenségi háború gazdasági problémái I703-I7II. Budapest: Akadémiai Kiadó, I $99 \mathrm{I}$.

Barta, János. A kétfejü sas árnyékában. Budapest: Gondolat, 1984.

Barta, János. A I 8. század története. Budapest: Pannonica, 2000.

Bérenger, Jean., Kecskeméti, Károly. Országgyülés és parlamenti élet Magyarországon I608-1918 . Budapest: Napvilág Kiadó, 2008.

Cseh, Géza. "Kyau lovagrendi landkomtur 17 I 4 . évi jelentése a Jászkunságról." In A JászNagykun-Szolnok Megyei Levéltár Évkönyve, Bd. I 9, edited by Maria ZádornéZsoldos, 263-279. Szolnok: A Jász-Nagykun-Szolnok Megyei Levéltár Évkönyve, 2004.

Cseh, Géza. "A Nagykunság leírása az i699. évi Pentz-féle összeírásban." In A JászNagykun-Szolnok Megyei Levéltár Évkönyve, Bd. 17, edited by Mária ZádornéZ Zsoldos, I 95-220. Szolnok: A Jász-Nagykun-Szolnok Megyei Levéltár Évkönyve, 2002.

Demel, Bernhard. "Der Deutsche Orden in Mähren und Schlesien." Jahrbuch der schlesischen Friedrich-Wilhelm-Universität zu Breslau 32 ( I 991): 29-68.

Demel, Bernhard. "Der Deutsche Orden seit I 525 - neue Aufgaben im Reich, in Österreich-Ungarn und seit 1929." In Vergangenheit und Gegenwart der Ritterorden. Die Rezeption der Idee und die Wirklichkeit, edited by Roman Czaja, Jürgen Sarnowsky (Ordines Militares. Colloquia Torunensia Historica XI), 77-I I 4. Toruń: TNT 200 I.

Demel, Bernhard. "Franz Ludwig von Pfalz-Neuburg als Hoch- und Deutschmeister (1694-1732) und Bischof von Breslau (1683-1732)." Jahrbuch der schlesischen Friedrich-Wilhelms-Universität zu Breslau 36/37 (1995/1996): 93-1 50.

Esze, Tamás. “A Tisza-vonal védelme a kurucok ellen I 703-ban.” In Rákóczi-tanulmányok, edited by Béla Köpeczi, Lajos Hopp and Ágnes R. Várkonyi, 597-68 I. Budapest: Akadémiai Kiadó, r 980.

Galewski, Dariusz. "Das Mäzenatentum des Fürstbischofs von Breslau Franz Ludwig von Pfalz-Neuburg (1683-1732)." Jahrbuch des Wissenschaftlichen Zentrums der Polnischen Akademie der Wissenschaften in Wien 2 (2009) [20 I I ]: 55-66.

Glassl, Horst. "Der Deutsche Orden in Burzenland und in Kumanien ( 12 I I - I 225)." Ungarn-Jahrbuch 3 (I 97 I): 26-47.

Glassl, Horst. "Ungarn im Mächtedreieck Ostmitteleuropas und der Kampf um das Zwischenland Schlesien." Ungarn-Jahrbuch 5 (1973): I 6-49.

Gonda, Imre., Niederhauser Emil. A Habsburgok. Budapest: Gondolat Könyvkiadó, I 987.

Hoensch, Jörg K. Geschichte Polens. Stuttgart: Eugen Ulmer, 1998.

Hoensch, Jörg K. Die Luxemburger. Eine spätmittelalterliche Dynastie gesamteuropäischer Bedeutung I308-1437. Stuttgart: Kohlhammer, 2000.

Hoffmann, Hans H. Der Staat des Deutschmeisters. Studien zu einer Geschichte des Deutschen Ordens im Heiligen Römischen Reich Deutscher Nation. München: Laßleben, 1964.

Horvath, Walter. "Die Deutschordensburgen des Burzenlandes." Deutsches Archiv für Landes- und Volksforschung 7 (1943): 446-452.

Illéssy, János. “A Jász-Kunság eladása a Német Lovagrendnek.” Századok 39 (I 905): 22-39. 
Illéssy, János. "Kaganeck utinaplója a Jászságról i 703-ban.” Nagy-Kunság XXII/3 I (1902): I-2; XXVII/32 (1 902$):$ I -3 .

Joachim, Erich. "König Sigmund und der Deutsche Ritterorden in Ungarn I 429-I 432." Mitteilungen des Instituts für Österreichische Geschichte 33 ( I 9 I 2): I 08 - I I 5.

Kakucska, Mária H. “Orczy Lőrinc fordítástöredéke II. Rákóczi Ferenc fejedelem „Emlékiratok” című munkájából." Erdélyi Múzeum Egyesület 68 (2007), 3-4: I 80-1 86.

Kalmár, János. "A Spanyol örökösödési háború." In A kora újkor története, edited by János Poór, 70-79. Budapest: Osiris Kiadó, 2009.

Kiss, István N. “Az I 707. évi Rákóczi-féle dicalis conscriptio.” In Rákóczi-tanulmányok, edited by Béla Köpeczi, Lajos Hopp and Ágnes R. Várkonyi, 87-I I 2. Budapest: Akadémiai Kiadó, I 980.

Kiss, József. “Das erste Jahrzehnt des Deutschen Ordens in Ungarn (1702-1712).” Acta Historica Akademiae Scientiarum Hungariae 30 ( 1984 ), I -2: 3-44.

Kiss, József. A Jászkun Kerület parasztsága a Német Lovagrend fóldesúri hatósága idején (I702-I73I). Budapest: Akadémiai Kiadó, I 979.

Kiss, József. A Pesti Invalidus Ház jászkunsági földesurasága, I73I-I745. Budapest: Akadémiai Kiadó, 1992.

Krollmann, Christian. Politische Geschichte des Deutschen Ordens in Preußen. Königsberg: Gräfe und Unzer, I 932.

Martini, Friedrich. "Der Deutsche Ritterorden und seine Kolonisten im Burzenland." Ungarn-Jahrbuch Io (1979): 4I-57.

Meltzer, Franz. Die Ostraumpolitik König Johanns von Böhmen. Ein Beitrag zur Ostraumfrage im I4. Jahrhundert. Jena: Gustav Fischer, I 940.

Müller, Georg E. "Die Ursachen der Vertreibung des Deutschen Ordens aus Burzenland und Kumanien im Jahre 1225.” Korrespondenzblatt des Vereins für siebenbürgische Landeskunde 48 (1925), 6-8: 42-68.

Öri, Péter. "A pestisjárványok demográfiai következménye a 17-I8. századi Magyarországon.” In Történeti Demográfiai Évkönyv 2005, I I 5-162. Budapest: KSH NKI, 2006.

Papcostea, Serban. "Terra Borza et ultra montes nivium. Ein gescheiterter Kirchenstaat und sein Nachlass." Siebenbürgisches Archiv 42 (20 I 3): 30-39.

Perlbach, Max. "Der Deutsche Orden in Siebenbürgen." Mitteilungen des Instituts für Österreichische Geschichte 26 (1 905): 41 5-430.

Pesty, Frigyes. A szörényi bánság és Szörény vármegye története. Vol. I. Budapest: Akadémia Könyvkiadó, I 877 .

Pósán, László. "Der Deutsche Orden im mittelalterlichen Ungarn.” Ordines Militares Colloquia Torunensia Historica. Yearbook for the Study of the Military Orders 17 (201 2): I $23-136$.

Pósán, László. “Die Münzprägung des Deutschen Ordens in Siebenbürgen." Acta Classica universitatis Scientiarum Debreceniensis 49 (2013): 73-79.

Pósán, László. A Német Lovagrend története a 13. században. Debrecen: Debrecen University Press, 1996. 
Pósán, László. “Ordinul Cavalerior Teutoni în Transilvania." Caiete de Antropologie Istorică IO (2011), 2: I17-136.

Pósán, László. "Sigismund und der Deutsche Orden." In Das Zeitalter König Sigmunds in Ungarn und im Deutschen Reich, edited by Tilmann Schmitt and Péter Gunst, 73-82. Debrecen: Debrecen University Press, 2000.

Prox, Alfred. "Die Burgen des Deutschen Ordens in Siebenbürgen." Siebenbürgisches Archiv I (1962): 29-62.

Rhode, Gotthod. Die Ostgrenze Polens. Politische Entwicklung, kulturelle Bedeutung und geistige Auswirkung. Vol. I: Im Mittelalter bis zum Jabre I4or. Köln, Graz: Böhlau, I 955 .

Soós, Imre. A jászkun redemptio 1745. Budapest 2006.

Spurny, Frantisek. "Letzter Soldatenruhm der Deutschordensfeste Eulenberg." In Acht Jahrhunderte Deutscher Orden in Einzeldarstellungen. Festschrift für Hochmeister P. Dr. Marian Tumler OT. zum 80. Geburtstag, edited by Klemens Wieser, 395-408. Bad Godesberg: Wissenschaftliches Archiv, 1967.

Srodecki, Paul. Antemurale Christianitatis. Zur Genese der Bollwerksrethorik im östlichen Mitteleuropa an der Schwelle vom Mittelalter zur Frühen Neuzeit. Husum: Matthiesen, 2015 .

Szijjártó, István M. A diéta. A magyar rendek és az országgyülés I708-1792. Budapest: Osiris Kiadó, 2005 .

Várkonyi, Ágnes R. A Királyi Magyarország I 54 I-1686. Budapest: Vince Kiadó, 1999.

Wirth, István. "A Jászkunság eladásának és visszaváltásának egyetemes történeti háttere." In Szolnok Megyei Múzeumok Évkönyve, I 49-I 50 . Szolnok: A Jász-Nagykun-Szolnok Megyei Levéltár Évkönyve, I98 I.

Zimmermann, Harald. Der Deutsche Orden in Burzenland. Eine diplomatische Untersuchung. Köln, Weimar, Wien: Böhlau, 2000.

\section{AbSTRACT}

The Teutonic Knights' Last Attempt at Returning to Hungary (1702-1731)

Subsequent to the expulsion of the Turks the Teutonic Knights made a last attempt (1702$-1731)$ at returning to Hungary after its abortive attempts in medieval times (1211-1228 and 1429-1432). Emperor Leopold I sold the Jazygian and the two Cumanian districts to the Order of Knights, who had participated in the anti-Turkish war form 1664 onwards. The Jazygian and Cumanian districts enjoyed privileges from medieval times on; being directly subordinate to the crown, the inhabitants had never been burdened by dues to the landed overlords. The population in the districts and the Hungarian estates at large promptly protested against the sale, but the Teutonic Order was unable to come into possession of the districts, for an anti-Habsburg uprising of the Hungarian noble estates broke out in 1703 led by the aristocrat Ferenc Rákóczi 2nd while the Imperial military were engaged in a war against France in the West. But the peace treaty putting an end to the 
uprising in 1711 did not confirm the position of the Knights, for the Emperor restored the Hungarian estates into their privileges and the Act of 1715 ruled that the transaction of 1702 had been unlawful and the districts should regain their liberties on condition that the estates pay back the purchase price the Knights had paid. This, however, did not materialize owing to the renewed warfare againsts the Turks. With regard to a possible compensation, the Teutonic Order did not implement any settlement or any economic investment in the Jazyigian or Cumanian districts, nor did it draw any profit from them. In 1731, the Grand Master sold the title to the Jazygian and Cumenian districts to the House of Invalids in Pest and the Teutonic Order left Hungary for good. 